\title{
Review: ACE inhibitors, but not angiotensin II receptor antagonists, reduce all cause mortality in diabetic nephropathy
}

Strippoli GF, Craig M, Deeks JJ, et al. Effects of angiotensin converting enzyme inhibitors and angiotensin II receptor antagonists on mortality and renal outcomes in diabetic nephropathy: systematic review. BMJ 2004;329:828.

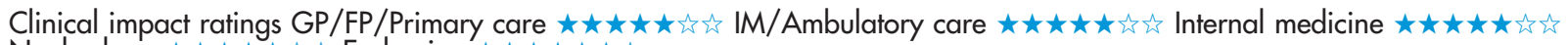

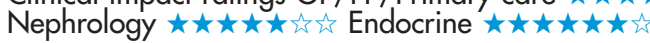

In patients with diabetic nephropathy, what are the effects of angiotensin converting enzyme (ACE) inhibitors and angiotensin II receptor antagonists (AlIRAs)?

\section{METHODS}

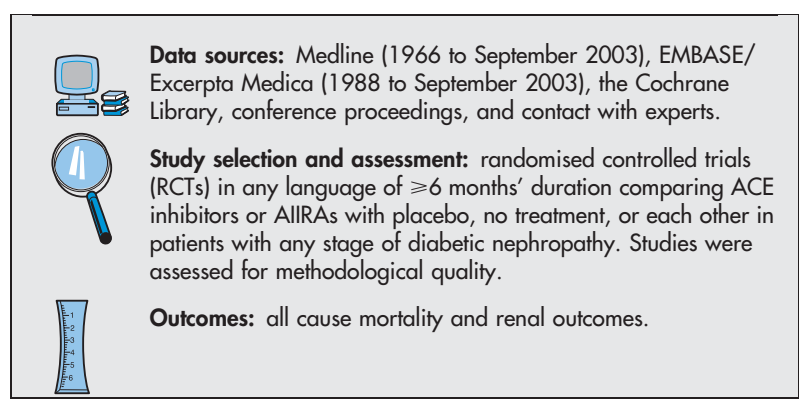

\section{MAIN RESULTS}

43 RCTs (follow up range 6-96 mo) met the selection criteria; 36 (4008 patients) compared ACE inhibitors with placebo or no treatment, 4 (3331 patients) compared AIIRAs with placebo or no treatment, and 3 (206 patients) compared ACE inhibitors with AIIRAs. ACE inhibitors, but not AIIRAs, reduced all cause mortality more than placebo or no treatment (table). The table shows the effects of ACE inhibitors and AIIRAs on renal outcomes. ACE inhibitors did not differ from placebo or no treatment for the rate of doubling of serum creatinine levels or of end stage renal disease. Data are lacking on the comparative effects of ACE inhibitors and AIIRAs on mortality and renal outcomes.

For correspondence: Dr G F Strippoli, University of Sydney, New South Wales, Australia. gfmstrippoli@aliceposta.it

Sources of funding: Australia-Europe Scholarship; NHMRC Centre for Clinical Research Excellence Grant; Italian Society of Nephrology.

\section{CONCLUSION}

In patients with diabetic nephropathy, angiotensin converting enzyme inhibitors, but not angiotensin II receptor antagonists, reduced all cause mortality compared with placebo.

\section{Commentary}

B oth ACE inhibitors and AllRAs have been noted for their antiproteinuric properties. ${ }^{1}$ However, it is unclear whether ACE inhibitors are more renoprotective than AllRAs, specifically in patients with diabetic nephropathy; and this is what Strippoli et al attempted to address.

In this review, the only large randomised trial to show renoprotection associated with ACE inhibitors involved patients with type 1 diabetes. ${ }^{2}$ On the other hand, the only study to show renoprotection associated with ACE inhibitors in type 2 diabetes is limited by the small number of patients and the fact that the patients did not fully satisfy the criteria for diabetic nephropathy. ${ }^{3}$ Furthermore, as the authors alluded to, the indirect nature of comparison between ACE inhibitors and AllRAs, using placebo as comparator, is a major limitation.

Much heterogeneity existed in the included studies, thus it is quite difficult to make conclusions and actual recommendations based on the data. Certainly, randomised controlled trials that directly compare ACE inhibitors and AllRAs in patients with diabetic nephropathy are needed to better settle the issues at hand. Until then, the only recommendations that can be derived from current published data are the use of ACE inhibitors in type 1 diabetes with nephropathy ${ }^{2}$ and the use of ACE inhibitors or AllRAs in type 2 diabetes with nephropathy. ${ }^{14}$

Edgar V Lerma, MD, FACP, FASN

University of Illinois at Chicago College of Medicine/ Associates in Nephrology, SC

1 Brenner BM, Cooper ME, de Zeeuw D, et al. N Engl J Med Chicago, Illinois, USA 2001;345:861-9.

2 Lewis EJ, Hunsicker LG, Bain RP, et al. N Engl J Med 1993;329:1456-62.

3 Ravid M, Savin H, Jutrin I, et al. Ann Intern Med 1993;118:577-81.

4 Lewis EJ, Hunsicker LG, Clarke WR, et al. N Engl J Med 2001;345:851-60.

Angiotensin converting enzyme (ACE) inhibitors or angiotensin II receptor antagonists (AllRAs) v placebo or no treatment (control)*

\begin{tabular}{|c|c|c|c|c|c|}
\hline Outcomes at at 6-96 months & Number of trials ( $n$ ) & Intervention $v$ control & Weighted event rates & $\operatorname{RRR}(95 \% \mathrm{CI})$ & NNT (Cl) \\
\hline \multirow{2}{*}{ All cause mortality } & $20(2383)$ & ACE inhibitors & $11.5 \% \vee 12.2 \%$ & $21 \%(1$ to 37$)$ & $157(44$ to $\infty)$ \\
\hline & 5 (3409) & AllRAs & $15.4 \% \vee 15.6 \%$ & $1 \%(-16$ to 15$)$ & NSt \\
\hline Progression from & $16(2010)$ & ACE inhibitors & $11 \%$ v $22 \%$ & $54 \%$ (29 to 70$)$ & 10 (6 to 23$)$ \\
\hline $\begin{array}{l}\text { microalbuminuria to } \\
\text { macroalbuminuria }\end{array}$ & $3(761)$ & AllRAs & $7.1 \%$ v $15 \%$ & $51 \%(25$ to 68$)$ & 14 (9 to 35$)$ \\
\hline Doubling of serum creatinine & $3(3251)$ & AllRAs & $18 \%$ v $22 \%$ & $21 \%(9$ to 31$)$ & $32(14$ to $\infty)$ \\
\hline \multirow[t]{2}{*}{ End stage renal disease } & $3(3251)$ & AllRAs & $17 \%$ v $19 \%$ & $22 \%$ (9 to 33$)$ & $37(16$ to $\infty)$ \\
\hline & & & & RBI (CI) & NNT (Cl) \\
\hline Regression from & $15(1888)$ & ACE inhibitors & $28 \% \vee 10 \%$ & $202 \%$ (83 to 398 ) & $6(4$ to 10$)$ \\
\hline $\begin{array}{l}\text { microalbuminuria to } \\
\text { normoalbuminuria }\end{array}$ & $2(670)$ & AllRAs & $26 \% \vee 18 \%$ & $42 \%$ (5 to 93$)$ & 13 (8 to 57$)$ \\
\hline
\end{tabular}

*Abbreviations defined in glossary; weighted event rates, RRR, RBI, NNT, and Cl calculated from data in article using a random effects model. †NS = not significant. 